\title{
RESOLUÇÃO DE PROBLEMAS DE CONGRUÊNCIA DE TRIÂNGULOS COM AUXÍLIO DO SOFTWARE GEOGEBRA
}

\author{
Francisco Ricardo Nogueira VAsConcelos ${ }^{1}$, Francisco Regis Vieira Alves ${ }^{1,2}$, \\ José Alberto Duarte Maia ${ }^{3}$, IVOneide Pinheiro De Lima ${ }^{4}$ \\ ${ }^{1}$ Instituto Federal de Educação, Ciência e Tecnologia do Ceará (IFCE) \\ ${ }^{2}$ Programa de Pós-graduação em Ensino de Ciências e Matemática \\ ${ }^{3}$ Universidade Federal do Ceará, ${ }^{4}$ Universidade Estadual do Ceará \\ $<$ frnv34@gmail.com>, <fregis@ifce.edu.br> \\ <alberto.duarte@mat.ufc.br>, <ivoneidepinheirodelima@gmail.com>
}

DOI: 10.21439/conexoes.v9i4.909

\begin{abstract}
Resumo. O nosso desafio como professor é possibilitar a melhoria da qualidade do ensino em Matemática buscando meios de garantir a formação de cidadãos capazes de reconhecer o seu papel na sociedade. Buscamos focar em ações que possibilitem o desenvolvimento das potencialidades cognitivas dos alunos no estudo de congruências de triângulos. Para isso, propomos o uso do software GeoGebra como ferramenta didática para as aulas de Geometria Plana, por entendermos que esse recurso favorece a aprendizagem do aluno e coloca o professor como mediador no processo de sistematização das ideias matemáticas necessárias para o desenvolvimento cognitivo do aluno. O objetivo do nosso estudo consiste em proporcionar aos alunos do curso de licenciatura em Matemática do IFCE - Campus Canindé, um minicurso sobre a utilização do GeoGebra como ferramenta didática para a resolução de problemas de Geometria Plana. Para a análise e coleta de dados foi realizado o estudo do PPC do curso e ministrado um minicurso introdutório de GeoGebra para 21 alunos matriculados na disciplina de Geometria. Os instrumentos de pesquisa foram: 02 questionários diagnósticos, a observação e o registro fotográfico. As análises dos resultados evidenciaram que os alunos se mostraram receptivos ao uso do software GeoGebra. O minicurso e as atividades didáticas tiveram um bom nível de aceitação por parte dos futuros professores de Matemática. As conclusões ressaltam que o uso do GeoGebra deve ser entendido como ferramenta didática alternativa para o ensino de Geometria, no sentido de proporcionar ao aluno, uma metodologia dinâmica e interativa para se aprender Matemática.
\end{abstract}

Palavras-chaves: GeoGebra. Ensino. Metodologia. Matemática. Geometria Plana.

Abstract. Our challenge as a teacher is possible to improve the quality of education in mathematics looking for ways to ensure the formation of citizens able to recognize their role in society. We seek to focus on actions that enable the development of cognitive potential of students in the study of congruence of triangles. We propose the use of GeoGebra software as a teaching tool for the plane geometry classes, because we believe that this feature promotes student learning and puts the teacher as a mediator in the systematization process of mathematical ideas necessary for the cognitive development of the student. The aim of our study is to provide students of the degree in Mathematics of IFCE - Campus Caninde, a short course on the use of GeoGebra as a teaching tool for solving plane geometry problems. For the analysis and data collection was performed PPC study the course and applied an introductory short course of GeoGebra to 21 students enrolled in Geometry discipline. THE research instruments were: 02 diagnostic questionnaires, observation and photographic record. Analysis of the results showed that students were receptive to the use of GeoGebra software. The short course and teaching activities had a good level of acceptance by the future teachers of mathematics. The conclusions point out that the use of GeoGebra should be understood as an alternative teaching tool for teaching geometry in order to provide the student with a dynamic and interactive approach to learning mathematics.

Keywords: GeoGebra. Education. Methodology. Mathematics. Plane Geometry. 


\section{INTRODUÇÃO}

O professor é o principal mediador entre o saber e o aprendiz, e como tal deve estar sempre apto a realizar mudanças no processo de ensino e aprendizagem. Nesse sentido, devemos buscar ferramentas pedagógicas que promovam uma boa interação entre o conhecimento a ser ensinado e o aluno, e é nessa perspectiva que propomos o uso do software GeoGebra como recurso pedagógico auxiliar para o ensino e aprendizagem de Geometria Plana.

O curso de licenciatura em Matemática do IFCE campus Canindé, em sua estrutura curricular, propõe em algumas disciplinas o uso de softwares matemáticos como recurso pedagógico alternativo, no entanto, nem sempre o aluno se sente apto a utilizá-lo, seja por não ter o conhecimento necessário, sejam por não dominar as suas potencialidades. Refletindo sobre esse fato, nos sentimos impulsionados a buscar soluções para uma melhor qualificação dos nossos alunos em relação ao uso de tecnologias voltadas para o ensino e aprendizagem de Matemática.

Para amenizar essa problemática, aprofundamos nossos estudos acerca do uso de softwares para o ensino de Geometria, por meio de ações pedagógicas que possibilitarão o desenvolvimento das potencialidades cognitivas dos alunos em relação ao estudo de congruência de triângulos. Nesse intuito, realizamos junto aos alunos, um minicurso intitulado "Resolução de problemas de geometria plana com o auxílio do software GeoGebra", utilizando dez atividades didáticas voltadas aos estudos dos conceitos geométricos do ensino básico, dando ênfase aos casos de congruência de triângulos e buscando verificar as concepções dos futuros professores em relação ao uso do referido software.

Propomos a inserção do software GeoGebra como um elemento aglutinador do processo de ensino e aprendizagem de Matemática por entendermos a importância de levarmos para sala de aula uma Matemática dinâmica, que trabalhe mais o raciocínio e a construção dos conceitos matemáticos em detrimento da aplicação direta de fórmulas e regras.

Para realizar o nosso estudo, nos apoiamos nos pressupostos teóricos da metodologia de resolução de problemas tendo em vista que esse método constitui uma estratégia didática fundamental para o desenvolvimento do raciocínio lógico matemático do aluno.

Nessa perspectiva, o uso do GeoGebra surge como uma alternativa didática para as aulas de Geometria Plana, no sentido de favorecer um clima de cooperação entre os alunos e contribuir, de modo construtivo, para a compreensão dos elementos conceituais de congruência de triângulos fundamentados na resolução de problemas.

Alguns softwares matemáticos, têm ajudado profissionais de diversas áreas do conhecimento, facilitando as suas tarefas, além de serem gratuitos e apresentarem vantagens com relação à economia de tempo e confiabilidade nos resultados, conforme ressaltam Lima e Lima (2000, p. 1),

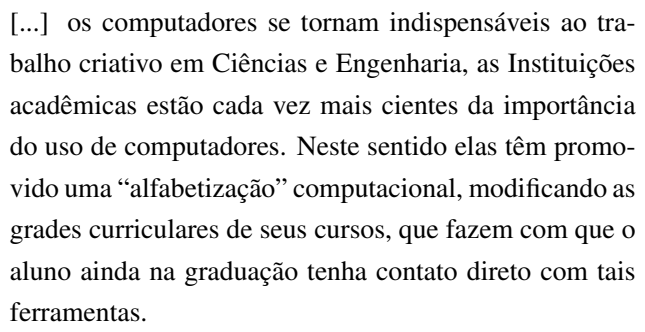

[...] os computadores se tornam indispensáveis ao trabalho criativo em Ciências e Engenharia, as Instituições acadêmicas estão cada vez mais cientes da importância do uso de computadores. Neste sentido elas têm promovido uma "alfabetização" computacional, modificando as grades curriculares de seus cursos, que fazem com que o aluno ainda na graduação tenha contato direto com tais ferramentas.

Nesse contexto, a inserção do software GeoGebra surge como uma alternativa didática para o ensino de Geometria Plana no sentido de reduzir os entraves epistemológicos do aluno em relação a essa disciplina.

As atividades didáticas foram desenvolvidas com alunos do $2^{\circ}$ semestre do curso de licenciatura em Matemática do Instituto Federal de Educação, Ciência e Tecnologia do Ceará (IFCE) campus Canindé onde foi utilizado o software GeoGebra como recurso pedagógico alternativo para a resolução de problemas que envolvem congruência de triângulos. A escolha do nosso público-alvo se justifica pelo fato de que a disciplina de Geometria Plana é ofertada nesse período do curso. Quanto ao tema proposto entendemos ser relevante devido muitos problemas relacionados à congruência de triângulos serem solucionáveis de maneira mais objetiva quando para isso utilizamos recursos gráficos de boa precisão.

O software GeoGebra, quando bem utilizado pelo professor, possibilita ao aluno um ambiente favorável para a construção e reelaboração da aprendizagem, dessa forma colaborando para o desenvolvimento de estruturas cognitivas que capacitam à generalização das informações conceituais, colocando acima de tudo, o professor como mediador no processo de organização e elaboração das ideias matemáticas e o aluno como um sujeito ativo desse processo. A esse respeito, Lenz, Ferraz e Ito (2007) ressaltam que a metodologia aplicada no ensino moderno de matemática, deverá está voltada ao uso de novas tecnologias computacionais dentro de uma perspectiva pedagógica inovadora e construtivista.

Experiências escolares com softwares têm mostrado que o seu uso efetivo e correto, podem levar a uma boa aproximação professor-aluno pautada na colaboração e interação, configurando o papel do professor sob a visão 
da busca constante de mudanças e atualização profissional (BRASIL, 1998).

Buscamos com esse trabalho, proporcionar uma elevação da autoestima dos estudantes, no que diz respeito ao desenvolvimento de ações didáticas relativas à resolução de problemas de Geometria Plana sob a perspectiva de uma aprendizagem significativa, que leva em consideração o conhecimento prévio dos alunos, conforme afirma Moreira, quando diz: "para que a estrutura cognitiva preexistente influencie e facilite a aprendizagem subsequente é preciso que seu conteúdo tenha sido apreendido de forma significativa, isto é, de maneira não arbitrária e não literal." (MOREIRA, 2006).

Assim, exploramos junto aos futuros professores de matemática, alunos do curso de licenciatura em Matemática do IFCE Campus Canindé matriculados na disciplina de Geometria Euclidiana Plana, as potencialidades do software GeoGebra como recurso pedagógico auxiliar para a resolução de problemas que envolvem congruência de triângulos.

O objetivo do nosso trabalho consistiu em verificar quais as implicações didáticas desse recurso como ferramenta didática a partir da resolução de problemas para a disciplina de Geometria Plana.

Para entendermos melhor essas implicações traçamos as seguintes ações específicas: caracterizamos por meio de atividades didáticas a importância do software matemático GeoGebra como recurso pedagógico auxiliar para o processo educacional; e reforçamos junto aos futuros professores de matemática, alunos da licenciatura em Matemática, o ensino e aprendizagem de Geometria Plana através da resolução de problemas por intermédio da aplicação do software GeoGebra.

Os objetivos acima delineados foram atingidos empregando-se como metodologia de pesquisa um estudo de caso de cunho qualitativo.

\section{FUNDAMENTAÇÃO}

Iniciamos esse tópico descrevendo um pouco sobre o software GeoGebra como ferramenta didática, suas implicações para o ensino de Geometria Plana ancorado na resolução de problemas, e os casos de congruência de triângulos.

Em relação ao ensino de Geometria Plana o GeoGebra representa uma proposta de mudanças para o ensino dessa disciplina, haja vista que, as novas tecnologias de comunicação e informação (TIC) são ferramentas potenciais de mudanças profundas nos diversos campos do conhecimento, e principalmente nos das construções e simulações.

Diante de tais mudanças, daremos ênfase ao ensino da Geometria, cujas propostas curriculares atuais suge- rem a inclusão dessa disciplina como prioritária na estrutura curricular do ensino básico com tratamento voltado ao uso das tecnologias da comunicação e informação. Segundo hohenwarter e hohenwarter (2009), no campo interativo da Geometria o GeoGebra deve funcionar como ferramenta de expansão e simulações, nos levando a entender que o software pode desenvolver no aluno competências necessárias a aquisição de novos conhecimentos no campo geométrico.

Para isso, é importante que o aluno se familiarize bem com essa ferramenta computacional, de modo a se tornar autônomo para desenvolver a capacidade de simular e interpretar problemas relacionados aos principais conteúdos da Geometria Plana, atributo este, indispensável para o desenvolvimento da motivação e do pensamento geométrico do aluno.

Com o apoio da ferramenta virtual GeoGebra, o aluno poderá se apropriar do conhecimento matemático e explorar a capacidade de solucionar problemas, conjecturar e fazer simulações nos campos da Geometria de forma dinâmica e interativa, formando um elo de ligação entre o conhecimento geométrico e o desenvolvimento de competências e habilidades essenciais para a formação inicial do professor de Matemática.

Nesse sentido, o software GeoGebra proporciona mudanças em relação ao ensino de geometria, pois envolve a construção e simulação de modelos geométricos, desde que o professor saiba como aplicá-la, uma vez que as tecnologias de informação e comunicação estão presentes no cotidiano dos alunos. Segundo $\mathrm{Ku}-$ siak, Pretes e Franzin (2012),

\footnotetext{
[...]As atividades desenvolvidas com o software Geogebra mostram-nos que é possível ensinar Geometria de forma dinâmica, tornando a aula instigante e atrativa, na qual o aluno participa, interage com seus colegas, e através de suas construções vai formulando o seu próprio conhecimento. Tudo isso vem a contribuir para o aumento das habilidades e potencialidades dos educandos, que nada mais é, do que nosso objetivo como futuros docentes (KUSIAK; PRETES; FRANZIN 2012 p. 8).
}

Conforme Brasil (1998), a construção do pensamento geométrico deve se dar durante o ensino básico e que a geometria não deve ser desvinculada da Matemática, e sim como elemento aglutinador do pensamento matemático e do raciocínio lógico dedutivo, proporcionando ao aluno estabelecer relações com a realidade em que vive.

De acordo com Lovis e Franco (2013), é cada vez maior a necessidade dos professores em utilizar recursos tecnológicos em sala de aula, contudo, se faz necessário proporcionar a esses sujeitos meios que os au- 
xiliem na compreensão e utilização desses recursos, e é nesse sentido que o GeoGebra pode auxiliar o professor no processo de ensino e aprendizagem de Geometria Plana.

Em relação a resolução de problemas, leivas (2013) reforça que essa técnica constitui uma metodologia de ensino e de aprendizagem defendida por vários pesquisadores em Educação Matemática, dentre eles destacamos Polya ao afirmar que os problemas estão na própria Matemática desde seus princípios, se tornando um elo motivador para o desenvolvimento da criatividade teórica e prática do aluno.

Desse modo o software GeoGebra surge como uma alternativa didática para o professor de Matemática, no sentido de potencializar o ensino de Geometria Plana. Polya (2010) defende que alguns tipos de problemas devem ser apresentados aos alunos no intuito de desenvolver habilidades para a resolução de problemas, ressaltando a importância da participação docente para o desenvolvimento do pensamento geométrico do aluno.

Segundo Lieban (2012), o GeoGebra é fundamental na resolução de problemas em Geometria para que o aluno possa levantar hipóteses, verificar a consistência dos seus argumentos e a validade de proposições, além disso é um excelente aplicativo para realizar construções geométricas, facilitando a visualização por parte do estudante dessas formalidades matemáticas de maneira mais natural.

O GeoGebra como software dinâmico, possibilita a visualização de uma mesma construção em diferentes disposições, facilitando a compreensão do comportamento geométrico dos elementos envolvidos no problema, mesmo aquelas mais intrínsecas e que muitas vezes passam desapercebidas em uma representação estática.

Lieban (2012) chama a atenção para o uso de recursos tecnológicos em sala de aula, argumentando que estes devem ser utilizados de forma cuidadosa, de modo a não se tornar um instrumento de dispersão. Para que isso não aconteça, é necessário um bom planejamento por parte do professor, cujas ações propostas possibilitem aos alunos reflexões sobre o objeto de estudo.

Nesse sentido, o GeoGebra se torna um grande aliado do professor como uma ferramenta pedagógica dinâmica facilitadora do planejamento de suas ações docentes, mediando o processo de ensino de forma lúdica, interativa e dinâmica.

No que concerne à congruência de figuras planas podemos intuitivamente enunciar que: "duas figuras planas são congruentes se uma delas puder ser deslocada sobre a outra de modo que ambas coincidam, sem que haja deformação de forma e medida" (REZENDE;
QUEIROZ, 2010). Assim podemos denotar duas figuras planas $A_{1}$ e $A_{2}$ congruentes por, $A_{1} \equiv A_{2}$.

Nesse caso, a congruência entre duas figuras planas verifica as propriedades: reflexiva: toda figura plana é congruente a ela mesma, ou seja, $A_{1} \equiv A_{1}$; simétrica: se uma figura plana $A_{1}$ é congruente a outra $A_{2}$, então $A_{2}$ é congruente a $A_{1}$, ou seja, $A_{1} \equiv A_{2} \leftrightarrow A_{2} \equiv$ $A_{1}$; e transitiva: se uma figura plana $A_{1}$ é congruente a outra $A_{2}$, e $A_{2}$ por sua vez são congruentes a $A_{3}$, então $A_{1} \equiv A_{3}$, ou seja, $A_{1} \equiv A_{2}$ e $A_{2} \equiv A_{3} \leftrightarrow A_{1} \equiv A_{3}$, representando uma relação de equivalência.

Por definição, triângulos congruentes nos permite definir uma correspondência biunívoca entre seus vértices tal que sejam congruentes os lados e os ângulos correspondentes. Utilizando o software GeoGebra podemos verificar o caso geral de congruência de triângulos, como ilustra a Figura 1

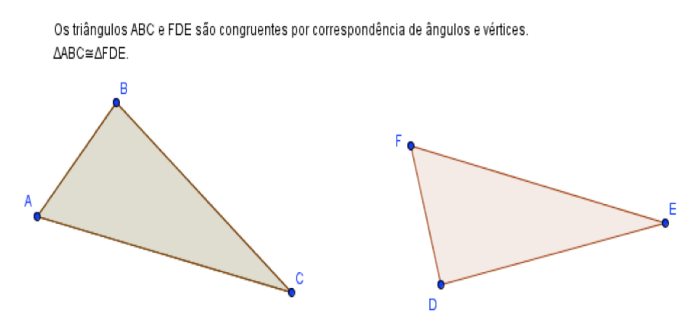

Figura 1: Cópia de tela do GeoGebra: caso geral de congruência de triângulos. Fonte: Pesquisa direta

Observamos nos triângulos ABC e FDE as correspondências $A \leftrightarrow F ; B \leftrightarrow D$ e $C \leftrightarrow E$, e consequentemente $\hat{A} \equiv \hat{F} ; \hat{B} \equiv \hat{D} ; \hat{C} \equiv \hat{E}$. Assim os lados $\overline{A B} \equiv \overline{F D} ; \overline{B C} \equiv \overline{D E} ; \overline{A C} \equiv \overline{F E}$. A partir dessas observações, podemos concluir que os triângulos $\mathrm{ABC}$ e FDE são congruentes, ou seja, $\overline{A B C} \equiv \overline{F D E}$.

Caso lado-ângulo-lado (L.A.L.) de congruência de triângulos: Dois triângulos que apresenta dois lados, e o ângulo entre esses lados ordenadamente congruentes, são congruentes, conforme mostra a Figura2.

Caso ângulo-lado-ângulo (A.L.A.) de congruência de triângulos: Dois triângulos que apresentam ordenadamente dois ângulos e o lado entre eles congruentes são congruentes, como mostra a Figura 3 .

Caso ângulo-lado-ângulo (L.L.L.) de congruência de triângulos: Dois triângulos que apresentam ordenadamente os três lados congruentes, são congruentes, como mostra a Figura 4 


\section{METODOLOGIA}
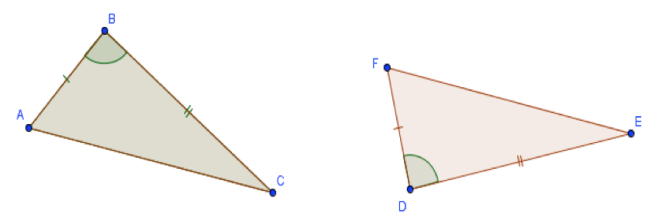

Figura 2: Cópia de tela do GeoGebra: caso L.A.L. de congruência de triângulos. Fonte: Pesquisa direta
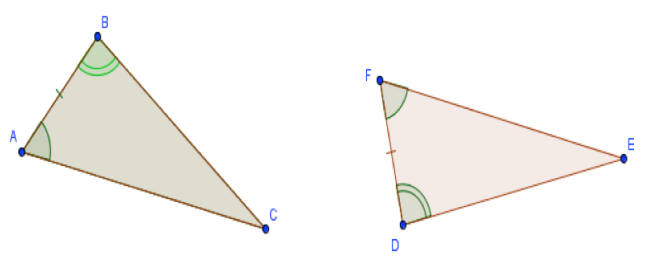

Figura 3: Cópia de tela do GeoGebra: caso A.L.A. de congruência de triângulos. Fonte: Pesquisa direta
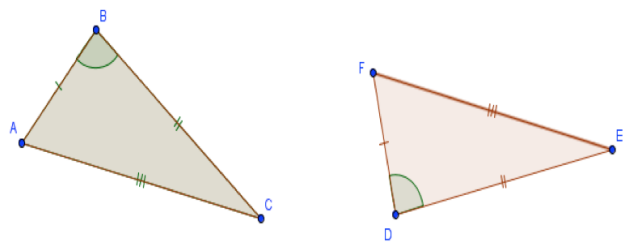

Figura 4: Cópia de tela do GeoGebra: triângulos semelhantes ABC e DEF. Fonte: Pesquisa direta
O trabalho de pesquisa se caracteriza como qualitativo do tipo estudo de caso, e os resultados provêm de um minicurso ministrado durante a disciplina de Geometria Euclidiana Plana para alunos do curso de licenciatura em Matemática do Instituto Federal de Educação, Ciências e Tecnologia do Ceará (IFCE), Campus Canindé - Ceará com carga horária de 20 horas aula.

Ao longo do desenvolvimento da pesquisa realizamos um levantamento bibliográfico com o objetivo de delinearmos os perfis dos autores que compunham nosso arcabouço teórico. O estudo desses autores nos proporcionou entender e refletir sobre qual seria a trajetória investigativa que devíamos seguir.

Esses estudos serviram de base para a formulação das ações didáticas que desenvolvemos antes de adentrarmos na seara do campo investigativo. Esses estudos ocorreram antes, durante e depois da pesquisa de campo.

De acordo com Nascimento, Coutinho e Sá (2010), a trajetória investigativa é marcada por escolhas do investigador, e assim o ato de pesquisar se torna interventivo, esse ato, mesmo sofrendo intervenção não tira o rigor na análise dos dados da pesquisa e caracteriza tal ambiente como espaço dinâmico de permanente construção entre o objeto pesquisado e o pesquisador.

Ao iniciamos o nosso trabalho de pesquisa, em junho de 2015, desenvolvemos e analisamos os objetivos e buscamos práticas investigativas fundamentadas em publicações acadêmicas que nos mostrassem teóricos e práticos que nos permitissem linearizar o nosso processo investigativo.

Optamos também pela metodologia de pesquisa de campo caracterizada por um estudo de caso, esse método é bastante utilizado em pesquisas científicas por caracterizar uma estratégia de pesquisa que permite uma investigação das características de situações no âmbito natural, possibilitando o delineamento mais amplo do conhecimento envolvido no caso pesquisado.

Esse tipo de pesquisa é bastante utilizado quando o pesquisador pretende estudar características particulares de algum objeto que possui um valor agregado em si mesmo (FIORENTINI; LORENZATO, 2006), e também quando o pesquisador se sente inclinado a investigar uma situação em particular com o objetivo de elucidar especificamente suas operacionalidades.

Para a elaboração das atividades, buscamos nos balizar em autores bem conceituados da nossa literatura, tais como Rezende e Queiroz (2010), Muniz Neto (2013), Polya (2010) e Moura (2012), haja vista que o nível dos problemas que propomos para o nosso minicurso foi fator determinante para a boa qualidade do 
nosso trabalho. Nesse sentido, optamos por atividades que explorassem os conceitos básicos da Geometria Plana, em especial os de Congruência de Triângulos.

Gostaríamos de deixar claro que um dos objetivos da nossa pesquisa é o de explorar bem os problemas geométricos de forma interativa e dinâmica, promovendo aos futuros professores de Matemática uma oportunidade de experimentar a ferramenta computacional GeoGebra como recurso pedagógico para o ensino de Geometria, bem como desenvolver juntamente com os mesmos uma análise crítica dos conteúdos ensinados em sala de aula, assim como a construção e reconstrução dos conceitos geométricos fundamentais.

Como instrumentos de coleta de dados utilizaramse questionários e imagens fotográficas. Registramos também as nossas atividades através da cópia de tela das atividades desenvolvidas pelos alunos e mediadas pelo pesquisador.

Optamos em nossa pesquisa em desenvolver e aplicar dois questionários: um antes e outro após a realização do minicurso com GeoGebra. O questionário apresenta-se como uma amostragem da população pesquisada, e tem como objetivo verificar a representatividade desses sujeitos, no nosso caso, os alunos matriculados na disciplina de Geometria Plana do curso de licenciatura em Matemática do IFCE, Campus Canindé.

A utilização de imagens produzidas por meio de fotografias representa um recurso imprescindível ao pesquisador no âmbito acadêmico e científico. Este artefato social produz registros de acontecimentos que possibilitam ao pesquisador imergir no contexto histórico, social e cultural de um povo. Segundo Müller (2006), esse instrumento de pesquisa é caracterizado como um testemunho, uma evidência, uma prova irrefutável de uma verdade observada no trabalho de campo.

\section{RESULTADOS E DISCUSSÃO}

Delinearemos esquematicamente as análises dos resultados da nossa trajetória investigativa partindo dos dados obtidos no minicurso. Começaremos mapeando o perfil dos sujeitos pesquisados (alunos licenciandos em Matemática), em seguida, apresentaremos a dinâmica do minicurso, as análises dos questionários diagnósticos aplicados aos alunos, e por fim, a descrição das atividades desenvolvidas com alunos em cada encontro do minicurso.

O perfil dos sujeitos pesquisados tomando como premissa as informações coletadas na ficha de inscrição e a primeira parte do questionário diagnóstico prépesquisa, foram 21 alunos selecionados, dos quais $43 \%$ (9) são do sexo masculino e $57 \%$ (10) do sexo feminino.
Ressaltamos que todos os alunos pesquisados ainda não atuam em sala de aula, e estão matriculados no período vespertino. Em relação à faixa etária, em sua maioria, $89 \%$ (16) dos alunos estão entre 18 e 30 anos, enquanto somente $11 \%(02)$ dos alunos estão na faixa etária de 31 a 40 anos, a faixa etária acima de 40 anos não pontuou.

A predominância de um público nessa faixa etária cursando a licenciatura sinaliza um crescimento na procura pelos jovens pela profissão de professor de Matemática.

Os resultados evidenciam um público, no geral, de perfil homogêneo, no sentido de se encontrar, em sua maioria, sem nenhuma experiência no campo do magistério. A partir de agora os alunos pesquisados serão identificados nas análises dos dados por A-01, A-02, A03, e assim por diante.

Os dados analisados mostram que $100 \%$ dos alunos nunca participaram de um curso ou minicurso sobre o software GeoGebra. Esse questionamento teve como objetivo verificar qual o nível de experiência prévia dos participantes em relação ao uso do software GeoGebra no ensino de Matemática ou áreas afins, pois o nível de conhecimento anterior agregado a novas informações favorece uma aprendizagem mais eficiente.

As análises reforçam a importância de se trabalhar essa ferramenta didática em sala de aula, haja vista que o uso de software no ensino de Matemática é uma pauta bastante discutida nos encontros nacionais e internacionais de pesquisadores em Educação Matemática.

A opinião dos alunos em relação ao uso do software no ensino de Matemática evidencia que esses sujeitos alimentam uma expectativa positiva em relação ao uso dessa metodologia, como pode ser evidenciado no seguinte relato de um dos alunos: "[...] é uma excelente ferramenta para dinamizar as aulas, pois nos ajuda no processo de formação." (A-07);

$\mathrm{Na}$ opinião dos alunos, conforme verificado em nossas análises, o uso de software no ensino da Matemática, em geral, favorece a aprendizagem auxiliando o professor no sentido de dinamizar e melhor elucidar os conteúdos a serem ensinados a partir de resolução de problemas, além disso, o uso de software proporciona um ambiente criativo e motivador em sala de aula, despertando nos alunos o desejo para aprender Matemática.

Perguntamos se em alguma das disciplinas da licenciatura em Matemática já haviam utilizado algum software matemático, e os alunos foram unânimes em responder que sim.

Quando indagados sobre qual o software utilizado, eles responderam o Winplot, e qual disciplina, responderam: fundamentos de Matemática I no primeiro se- 
mestre. Vale ressaltar que nenhum aluno até o momento tinha utilizado o software GeoGebra. Confirmando a necessidade de um curso básico de GeoGebra durante a formação inicial desses futuros professores.

No que diz respeito à expectativa dos alunos em relação ao minicurso, as falas dos respondentes mostra o nível de interesse em aprender uma nova ferramenta didática para o ensino de Matemática, deixando clara a importância de novos conhecimentos que venham a contribuir para sua formação docente. Vide o seguinte comentário: "Espero conhecer esta ferramenta e suas aplicações para enriquecer minha formação e ampliar minhas possibilidades de lecionar a disciplina de matemática." (A-08).

No cômputo geral, o minicurso foi planejado no sentido de traçar novos caminhos que levassem os alunos, futuros professores de Matemática, a refletir sobre a contribuição do software GeoGebra para a sua formação docente, no sentido de "provocar" nesses sujeitos uma mudança de postura em relação a sua prática docente em sala de aula.

Transcrevemos a seguir as falas de alguns alunos em relação à resolução das atividades sem a utilização do software GeoGebra: "Sem o GeoGebra temos que recorrer ao desenho de mão livre e sem ser manipulável." (A-08); "Desenhar a mão é mais difícil bem como as medidas não ficam precisas." (A-21).

Finalizamos o minicurso com a aplicação do último instrumento de pesquisa o teste diagnóstico póspesquisa para avaliação do minicurso, que teve como objetiva verificar o nível de satisfação dos participantes em relação às atividades didáticas utilizadas, a sua importância para a formação inicial dos participantes, qual às expectativas iniciais, e quais os pontos positivos e negativos dessa metodologia para sua formação docente. Delineamos em seguida esses resultados.

Aplicamos o último questionário no intuito de avaliar a dinâmica desenvolvida no minicurso. O questionário foi aplicado para os 16 alunos presentes no terceiro encontro.

Perguntados sobre qual o grau de importância do minicurso para a sua formação acadêmica e os resultados mostraram que 15 (94\%) alunos consideraram que o minicurso foi ótimo e apenas 01 aluno $(6 \%)$ o considerou bom, enquanto as opções regular e ruim não foram pontuadas.

Os resultados apresentados são reforçados pelos seguintes relatos, “[...] vai nos auxiliar muito até mesmo para nossas aulas de geometria e principalmente para nosso conhecimento." (A-19); “Afinal poderei usar o software para uma aula mais dinâmica sem contar nas inúmeras melhorias que ele trouxe para o meu entendi- mento pessoal sobre a geometria." (A-16).

Quando perguntamos após o minicurso qual a opinião deles em relação ao uso de software no ensino de Matemática, os resultados mostraram que eles puderem confirmar através do minicurso que os softwares exercem grande contribuição para a aquisição de novos registros teóricos no que concerne ao ensino de Geometria Plana.

As argumentações seguintes tecidas pelos alunos reforçam a nossa afirmativa, "É de grande auxílio, pois facilita ao aluno a visualização e compressão dos conteúdos, principalmente na área de geometria." (A-14); "É muito importante utilizar o GeoGebra pois ele oferece uma visão nova para o aluno, e consegue auxiliar melhor os conteúdos." (A-09).

Questionados se o minicurso havia atendido as suas expectativas, todos os participantes responderam que "sim".

Seguem algumas respostas dadas pelos alunos, "Eu não sabia como funcionava o software e também não sabia como aplicar em sala de aula." (A-15); "Aprendi de forma teórica, prática e fácil como usar o software GeoGebra para o ensino de Matemática." (A-10); "Eu não sabia como funcionava o software e também não sabia como aplicar em sala de aula." (A-15).

Em relação aos aspectos positivos, eles assinalaram que o software GeoGebra é uma ferramenta didática importante para a sua formação acadêmica, e que irão utilizá-lo com seus alunos em sala de aula como futuros professores.

As falas a seguir mostram o sentimento dos alunos em relação ao software GeoGebra como ferramenta didática: "O minicurso foi muito importante para a nossa formação nos trazendo bastante conhecimento." (A17). Em relação aos pontos negativos os alunos pesquisados lamentaram a falta de tempo e o fato de nem todos os alunos disponibilizarem de um notebook. Repare a fala de um aluno, "A falta de não ter notebook para todo mundo." (A-07).

Entendemos que no geral, o minicurso bem proveitoso para os alunos, essa conclusão é corrobora com os dados analisados anteriormente. Observamos também que durante as atividades do minicurso os alunos trocaram muitas informações e apresentaram dúvidas quanto a melhor solução para cada atividade desenvolvida, valorizando pedagogicamente cada momento do encontro, pois a dinâmica do minicurso permitia a troca de conhecimentos entre os alunos, mas sempre mediados pelo pesquisador.

Durante todo o minicurso os alunos se mostraram participativos e empolgados no que concerne ao desenvolvimento do processo de aprendizagem do soft- 
ware GeoGebra, dando sugestões e formulando conceitos, mostrando-se participativos e ativos em relação ao processo de construção das atividades didáticas, levantando hipóteses, interpretando e reformulando questionamentos de modo a se obter uma melhor saída para cada atividade didática proposta.

Reforçamos que os alunos participantes do minicurso se mostraram bem receptivos as orientações contidas no nosso contrato didático e que pretendem levar essa ferramenta didática para as suas aulas de Matemática.

Assim, consideramos que o nosso minicurso foi uma oportunidade positiva para agregar valores a formação acadêmica desses alunos no sentido de favorecer experiências diferenciadas como proposta para o ensino de Matemática nas escolas de ensino básico.

\section{CONSIDERAÇÕES FINAIS}

Nesse estudo, buscamos junto a fontes bibliográficas que tratam do tema GeoGebra, esclarecer a importância da inserção do uso do software GeoGebra nas aulas de Geometria para a formação de professores de Matemática, especialmente na fase da formação inicial.

Para tanto, procuramos ser o mais abrangente possível e pouco superficial na escolha das atividades didáticas, e para isso utilizamos bibliografias de referência nas universidades brasileiras. As atividades propostas envolviam os principais teoremas e axiomas da Geometria Plana, priorizando o uso de construções geométricas elementares em cada solução a ser desenvolvida. Cada atividade do minicurso foi previamente analisada, testada e experimentada pelo pesquisador, antes de ser proposta ao aluno, caso contrário, poderia correr o risco dos objetivos propostos não serem alcançados, e consequentemente, representar um prejuízo em relação à aquisição de aprendizagem dos conteúdos pelos discentes.

Durante o minicurso os alunos tiveram a oportunidade de refletir e discutir sobre a importância dos softwares no ensino de Matemática, particularmente do GeoGebra. De acordo com os dados analisados as atividades propostas e o software GeoGebra obtiveram um boa aceitação pelos alunos, levando-nos a considerar que, em geral, as atividades didáticas aplicadas foram e serão importantes para a formação acadêmica dos participantes, levando-nos a refletir que os futuros docentes acreditam e apoiam o software GeoGebra como um recurso pedagógico eficaz para o ensino de Geometria.

Nesse sentido, podemos considerar que os objetivos delineados para esse estudo foram alcançados e os seus questionamentos elucidados a partir de cada atividade proposta no minicurso se utilizando para isso de objetos matemáticos construídos com o software GeoGebra.

Entendemos que a nossa pesquisa está concluída de acordo com os objetivos traçados e dentro do contexto ao qual foi proposto, e esperamos com esse trabalho termos contribuído da melhor forma possível para a melhoria do ensino de Geometria, e que os nossos estudos possa ser usado como fundamentação para futuros estudos no campo da Matemática.

\section{REFERÊNCIAS}

BRASIL. Parâmetros curriculares nacionais $\left(6^{\circ}\right.$ ao $9^{\circ}$ ano): matemática. Secretaria de Educação Fundamental, 1998. Disponível em: <http: //portal.mec.gov.br/seb/arquivos/pdf/matematica.pdf> Acesso em: 30 jun. 2015.

FIORENTINI, D.; LORENZATO, S. Investigação em educação matemática: percursos teóricos $e$ metodológicos. Campinas: Autores associados, 2006. (Coleção formação de professores).

HOHENWARTER, m.; HOHENWARTER, j. Ajuda Geogebra: manual oficial da versão 4.4. Tradução e adaptação para o português de Portugal. São Paulo: Projeto GeoGebra online, 2009. Disponível em: <http://static.geogebra.org/help/docupt_PT.pdf> Acesso em: 17 abr. 2015.

KUSIAK, R. S.; PRETES, R. F.; FRANZIN, D. R. F. A utilização do software geogebra no ensino de geometria plana: uma experiência PIBID. In: Anais do $1^{o}$ Seminário Nacional de Inclusão Digital. Passo Fundo: [s.n.], 2012. Disponível em: <http://gepid.upf.br/senid/2012/anais/96196.pdf> Acesso em: 13 maio 2015.

LEIVAS, J. C. P. Resolução de problemas geométricos usando o geogebra. I CONGRESSO DE EDUCACIÓN MATEMÁTICA DE AMÉRICA CENTRAL Y EL CARIBE - I CEMACYC. http://www.centroedumatematica.com/memoriasicemacyc/200-379-1-DR-T.pdf, 2013. Acesso em: 21 mar. 2015.

LENZ, E. A.; FERRAZ, I. R.; ITO, G. C. Ferramentas de informática: usando os recursos da informática para ensino e aprendizagem de Matemática. 2007. 30 f. Disponível em: <http://www.ensino.eb.br/portaledu/ conteudo/artigo8653.pdf> Acesso em: 10 maio 2015.

LIEBAN, D. E. Resolução de problemas geométricos com o software geogebra, valorizando a interatividade no processo de ensino-aprendizagem. 
RESOLUÇÃO DE PROBLEMAS DE CONGRUÊNCIA DE TRIÂNGULOS COM AUXÍLIO DO SOFTWARE GEOGEBRA

CONFERENCIA LATINO AMERICANA DE GEOGEBRA 2012. Uruguay, 2012. Disponível em: <http://www.geogebra.org.uy/2012/actas/40.pdf> Acesso em: 01 fev. 2015

LIMA, L. d. A.; LIMA, A. G. B. O uso do software matematica como ferramenta de auxilio ao ensino de graduação em engenharia mecânica. http://www.dee.ufrj.br/VIIEEE/VIEEE/enanais.htm, 2000. Acesso em: 8 maio 2015.

LOVIS, K. A.; FRANCO, V. S. Reflexões sobre o uso do geogebra e o ensino de geometria euclidiana. Informática na educação: teoria \& prática, v. 16, n. 1, p. 149 - 160, 2013. Disponível em: $<$ http://seer.ufrgs.br/index.php/InfEducTeoriaPratica/ article/view/26104/25946> Acesso em: 20 mar. 2015.

MOREIRA, M. A. A teoria da aprendizagem significativa e sua implantação em sala de aula. Brasília: Editora Universidade de Brasília, 2006, 2006.

MOURA, E. M. F. d. Geometria: problemas sem problemas. Rio de Janeiro: Editora XYZ,2012. 503p, 2012.

MUNIZ NETO, A. C. Geometria. Rio de Janeiro: Editora SBM, 2013. 471p, 2013.

MüLLER, T. M. P. A fotografia como instrumento e objeto de pesquisa: imgens do estado e da imprensa do cotidiano de crianças e adolescentes do serviço de assistência ao menor (sam). $29^{\circ}$ Reunião Anual da Anped, 2006, Caxambu. Educação, Cultura e Conhecimento na contemporaneidade: desafios e compromissos. Caxambu : Anped, 2006. v. 01. http://www.anped.org.br/reunioes/29ra/trabalhos/trabalho/GT021796-Int.pdf, 2006. Acesso em: 06 fev. 2015.

NASCIMENTO, M. L. do; COUTINHO, A. P. C.; SÁ, D. A. de. Análises de produções escritas sobre abrigos para crianças e adolescentes. Rio de Janeiro: São João Del Rei, 2010, 2010. Disponível em: <http://www.ufsj.edu.br/portal2-repositorio/File/ revistalapip/volume5_n1/sumario_51.pdf $>$ Acesso em: 3 mar. 2015

POLYA, G. Sobre a resolução de problemas de matemática na high school. KRULIK, Stephen; CORBO, Olga. A resolução de problemas na matemática escolar. Tradução de Hygino $H$. Domingues; Robert E. Reys. São Paulo, SP: Atual, 2010. 343 p., 2010. 